\title{
Determination of Major, Minor, and Trace Elements in Jadeite using Scanning micro-X-ray Fluorescence
}

\author{
Edward P. Vicenzi ${ }^{1,2}$ and Thomas Lam ${ }^{1}$ \\ 1. Smithsonian Institution, Museum Conservation Institute, Suitland, MD, USA \\ 2. National Institute of Standards and Technology, Materials Measurement Science Division, \\ Gaithersburg, MD, USA
}

Jade is found as a lithic archaeological artifact with principal sources in Asia and Mesoamerica. One variety is comprised of jadeite $\left(\mathrm{NaAlSi}_{2} \mathrm{O}_{6}\right)$ and was valued by prehistoric artisans for both its visual and physical properties [1]. In this study, we have examined a bulk specimen from Japan (J1957) that has been cut, ground, and polished flat on one face [2].

A Bruker M4 Tornado scanning micro-XRF equipped with a Mo (collimated to $1 \mathrm{~mm}$ ) and Rh (polycapillary tube with a $20 \mathrm{um}$ spot at Mo $\mathrm{K}_{\alpha}$ ) x-ray sources, was operated at $50 \mathrm{kV}$ for spectroscopic imaging. X-ray fluorescence was collected using two opposing $60 \mathrm{~mm}^{2}$ silicon drift detectors (SDD). The irregularly shaped specimen was pressed into modeling clay with the aid of hand press, to maintain a near zero degree tilt of the polished face before being examined under vacuum.

An overview of the compositional imaging and associated spectra of J1957 reveals that some trace elements can be imaged without significant interference arising from x-ray diffraction (Fig. 1). Apart from increasing x-ray throughput, the dual detector geometry reduces the magnitude of such diffraction artifacts. Despite the thin architecture of the SDD, a few hundred $\mu \mathrm{m}$ in thickness, both Sn and Ba K lines were observed, above 25 and $32 \mathrm{keV}$ respectively. Detection of these peaks was unexpected owing to the diminished quantum efficiency of the SDD at these high energies coupled with their low concentration in the specimen.

A subset of the specimen was imaged at higher spatial resolution revealing $\mathrm{Cr}, \mathrm{Mn}, \mathrm{Ni}, \mathrm{Mg}$, and $\mathrm{Ca}$ enrichment in veins (Fig. 2 A-D). Among the initial chemical phases identified by multivariate statistical processing were two that matched the major element atomic proportions of jadeite. These two phases were combined and reprocessed. The FP results for jadeite compare favorably to the major and minor compositions determined by standards-based electron beam analysis (Table 1), particularly given the large difference in volume the two analyses represent. Moreover, the $\mu$ XRF cation proportions on the basis of 6 oxygens are equivalent to the electron beam result. The most significant difference is with respect to $\mathrm{Mg}$, where the $\mu \mathrm{XRF}$ reports a zero concentration compared to $1.4 \mathrm{wt} \%$ by EPMA. Upon inspection of the XRF spectrum, the Mg detection limit is not the issue, but rather an overestimate of the Rh scatter background. Five elements are reported at the 10s of ppm level (Mn, Ni, Sr, Zr, and Ba), some with spectral overlaps (Fig. 3 A,B). With such sensitivity for trace elements, their ratios offer a potential tool for heritage scientists to test jadeite provenance. While previous trace element studies of jadeite employed locally destructive methods, e.g. laser ablation ICP-MS [2], $\mu$ XRF is non-destructive, an important virtue for cultural heritage science [3].

\section{References:}

[1] F Lange, "Precolumbian jade: New geological and cultural interpretations," F Lange, editor (1993)

[2] T Morishita et al, Island Arc 16 (2007), 40-56 
[3] We acknowledge the Freer Gallery of Art for access to J1957 \& L. Humenuck for light microscopy

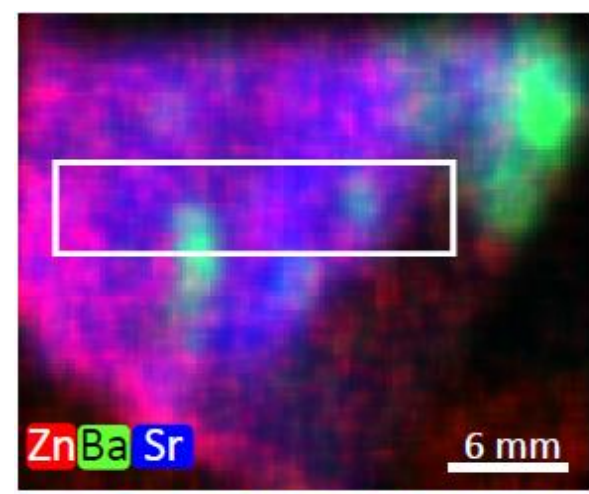

Figure 1. Trace element image overview of jadeite fragment J1957 (Zn-red; Ba-green; Sr-blue) using a collimated Mo x-ray source and a step size of $250 \mu \mathrm{m}$.
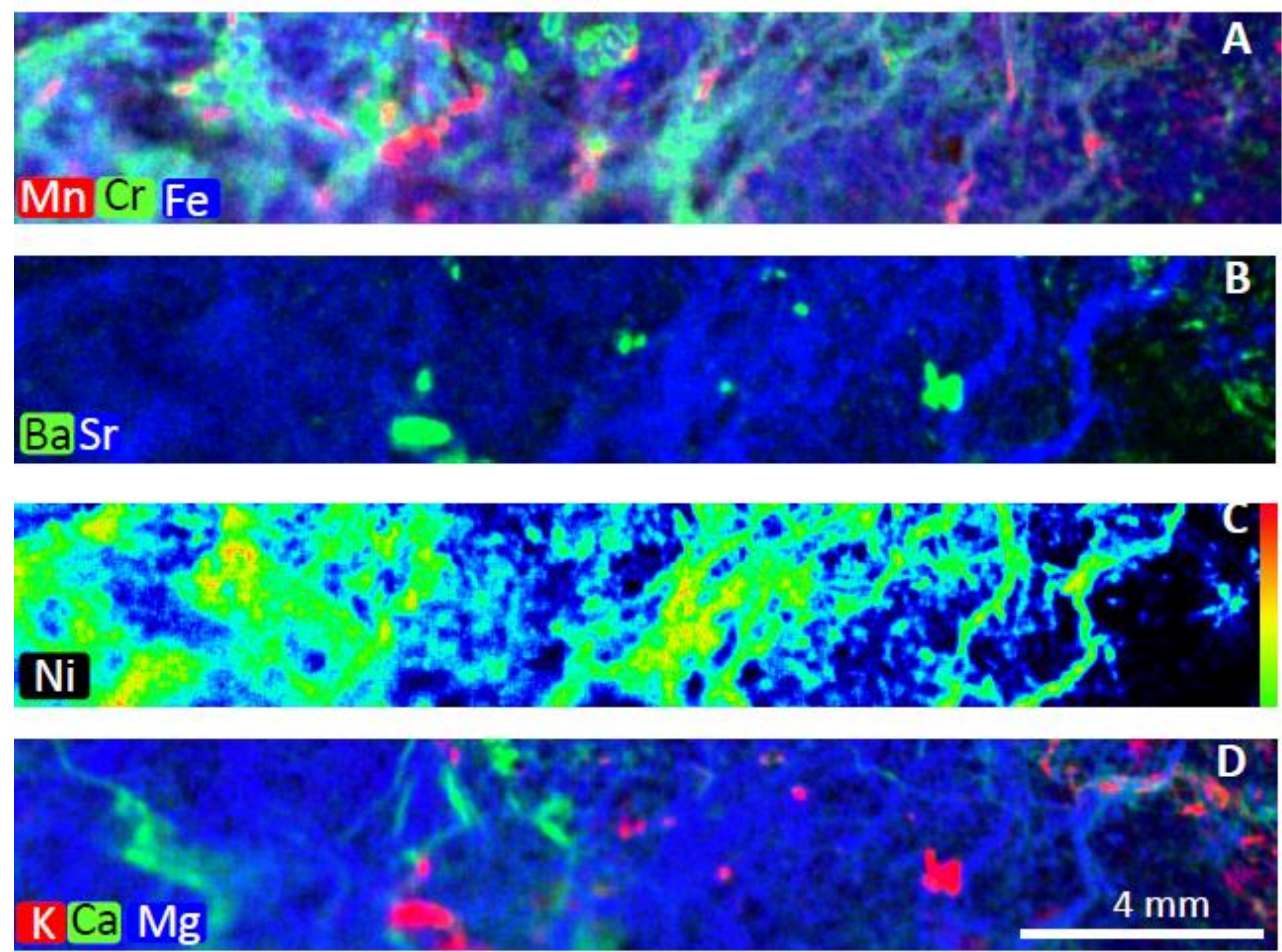

Figure 2. Minor and trace element image overlays using an unfiltered Rh x-ray source with a polycapillary optic and a step size of $15 \mu \mathrm{m}$. A) Mn-red; Cr-green; Fe-blue; B) Ba-green; Sr-blue; C) Ni-rainbow scale; D) K-red; Ca-green; $\mathrm{Mg}$-blue.

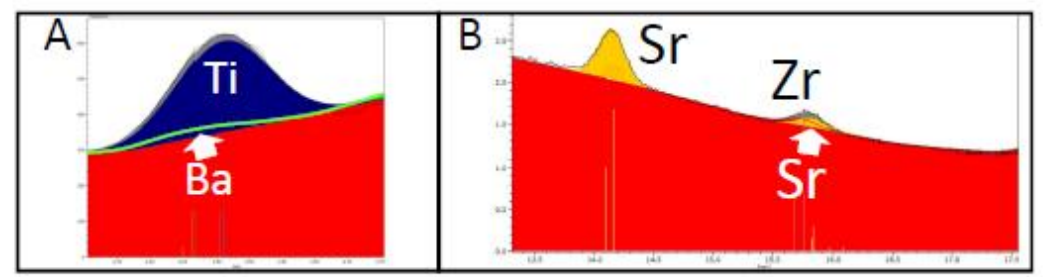

Figure 3. Graphical representation of spectral deconvolution of trace elements x-ray line interferences (red-x-ray scatter background; gray-fit spectrum). A) Ba $\mathrm{L}_{\alpha}(37 \mathrm{ppm})$ on $\mathrm{Ti} \mathrm{K}_{\alpha}(132 \mathrm{ppm})$ at $4.5 \mathrm{keV}$; B) $\mathrm{Zr} \mathrm{K} \mathrm{K}_{\alpha}$ (13 ppm) on $\mathrm{Sr} \mathrm{K}_{\beta}(87 \mathrm{ppm})$ at $15.8 \mathrm{keV}$.
Table 1. Quantitative jadeite analyses by FPbased $\mu \mathrm{XRF}$ and standards-based electron beam EDS.

\begin{tabular}{|c|c|c|}
\hline \\
\hline & $\mu \mathrm{XRF}$ & e-beam \\
\hline \multicolumn{2}{|c|}{ Avg. phase area } & $N=29$ \\
\hline $\mathrm{SIO}_{2}$ & 59.472 & 58.40 \\
\hline $\mathrm{TiO}_{2}$ & 0.022 & 0.04 \\
\hline $\mathrm{Al}_{2} \mathrm{O}_{3}$ & 26.137 & 23.23 \\
\hline $\mathrm{Cr}_{2} \mathrm{O}_{3}$ & 0.021 & 0.04 \\
\hline $\mathrm{FeO}^{*}$ & 1.010 & 0.76 \\
\hline $\mathrm{CaO}$ & 3.353 & 1.79 \\
\hline $\mathrm{MgO}$ & 0.000 & 1.37 \\
\hline $\mathrm{Na}_{2} \mathrm{O}$ & 14.774 & $\underline{14.60}$ \\
\hline Total & 104.79 & 100.18 \\
\hline \multicolumn{3}{|c|}{ cations per 6 oxygens } \\
\hline $\mathrm{Si}$ & 1.939 & 1.981 \\
\hline $\mathrm{Ti}$ & 0.001 & n.d \\
\hline Al & 1.005 & 0.980 \\
\hline $\mathrm{Cr}$ & 0.001 & n.d \\
\hline $\mathrm{Fe}^{*}$ & 0.028 & 0.006 \\
\hline $\mathrm{Ca}$ & 0.117 & 0.027 \\
\hline $\mathrm{Mg}$ & 0.000 & 0.032 \\
\hline $\mathrm{Na}$ & $\underline{0.934}$ & $\underline{1.001}$ \\
\hline \multirow[t]{2}{*}{ total } & 4.024 & 4.029 \\
\hline & $p p m$ & \\
\hline K & 349 & \\
\hline $\mathrm{Mn}$ & 27 & \\
\hline $\mathrm{Ni}$ & 28 & \\
\hline $\mathrm{Sr}$ & 87 & \\
\hline $\mathrm{Zr}$ & 13 & \\
\hline $\mathrm{Ba}$ & 37 & \\
\hline
\end{tabular}

